This is the preprint version of an article published in Philosophical Investigations 40 (1), 4063. The final publication is available at Wiley Online: http://onlinelibrary.wiley.com/doi/10.1111/phin.12129/abstract. Please cite the published version only.

\title{
Wittgenstein and Objectivity in Ethics. A Reply to Brandhorst
}

\author{
Benjamin De Mesel, KU Leuven
}

\begin{abstract}
In "Correspondence to Reality in Ethics", Mario Brandhorst examines the view of ethics that Wittgenstein took in his later years. According to Brandhorst, Wittgenstein leaves room for truth and falsity, facts, correspondence and reality in ethics. Wittgenstein's target, argues Brandhorst, is objectivity. I argue (1) that Brandhorst's arguments in favour of truth, facts, reality and correspondence in ethics invite similar arguments in favour of objectivity, (2) that Brandhorst does not recognise this because his conception of objectivity is distorted by a Platonist picture, and (3) that he misinterprets the passage which he takes to support a Wittgensteinian case against objectivity.
\end{abstract}

\section{Introduction}

In his interesting and thought-provoking article entitled "Correspondence to Reality in Ethics", Mario Brandhorst examines the view of ethics that Wittgenstein took in his later years. ${ }^{1}$ According to Brandhorst, the later Wittgenstein did not wish to deny that there is room for truth and falsity in ethics, that there are ethical facts, and that an ethical reality corresponds to ethical judgements. Rather, he wanted to warn us against the temptation to understand "truth", "falsity", "fact", "reality" and "correspondence" in the ways in which we understand these notions in the context of a physical theory. These ways have no counterpart in ethics, but that does not imply that it makes no sense to speak of "truth", "falsity", "fact", "reality" and "correspondence" in ethics. Brandhorst aims to show how Wittgenstein's later thought allows us to make sense of them in an ethical context.

In the following, I will assume that Brandhorst's arguments are sound and that his claims about how the later Wittgenstein thought about truth, facts, reality and correspondence in ethics are true. I will show, however, that these arguments and claims do not support Brandhorst's

\footnotetext{
${ }^{1}$ Brandhorst (2015).
} 
This is the preprint version of an article published in Philosophical Investigations 40 (1), 4063. The final publication is available at Wiley Online: http://onlinelibrary.wiley.com/doi/10.1111/phin.12129/abstract. Please cite the published version only.

conclusion. In his conclusion, he says that claims to objectivity in ethics, rather than claims to truth, facts, reality or correspondence, are Wittgenstein's real target and that this is confirmed by a passage from Wittgenstein's conversations with Rush Rhees in $1945 .^{2}$ I will argue that the passage does not confirm this and that Brandhorst's arguments actually support a case for objectivity in Wittgensteinian ethics rather than a case against it. That is, arguments similar to those invoked by Brandhorst can be (and have been) used to defend the claim that, according to the later Wittgenstein, there is room for objectivity in ethics. If Brandhorst's arguments succeed, they will allow for (rather than prevent) talk of objectivity in ethics.

I will proceed as follows. Firstly, I will present a summary of the considerations, reasons and arguments used by Brandhorst to defend the claim that there is room for truth, facts, correspondence and reality in the later Wittgenstein's ethical thought (section II). Secondly, I will show how these considerations, reasons and arguments can be and have been used to defend conceptions of objectivity in ethics (section III). Thirdly, I will argue that Brandhorst takes these arguments to speak against, rather than for, objectivity because his understanding of objectivity is distorted by a Platonist picture that is very similar to the pictures that he explicitly warns against when he discusses truth, facts, reality and correspondence in ethics (section IV). Fourthly, I will show how Brandhorst misreads the passage from Wittgenstein's conversations with Rhees, which he takes to support his case against objectivity (section V).

\section{Brandhorst's Arguments}

Let me start with an outline of Brandhorst's arguments, reasons and considerations (for a full account and defence, I am happy to refer to Brandhorst's article). I will structure them in a different way than Brandhorst's, namely, in a way that will help me to clarify, in section III, how they may contribute to a case for, rather than against, objectivity. Brandhorst combines these arguments, reasons and considerations in order to support the claim that there is room for truth, facts, reality and correspondence in the later Wittgenstein's thought about ethics.

\footnotetext{
${ }^{2}$ Ibid., 247-248.
} 
This is the preprint version of an article published in Philosophical Investigations 40 (1), 4063. The final publication is available at Wiley Online: http://onlinelibrary.wiley.com/doi/10.1111/phin.12129/abstract. Please cite the published version only.

(i) In a different way, different kinds, in a different sense. Brandhorst recognises that we cannot speak of truth, facts, reality and correspondence in ethics in the way in which we speak of them in, for example, physics. His overarching argument is that this does not mean that we cannot speak of these things in ethics at all. "Truth", etc. are used in different ways in different language games. ${ }^{3}$ Ethical outlooks can be divided into true and false, but true and false "in a different sense". ${ }^{4}$ We must distinguish between "different kinds of correspondence". 5 Brandhorst refers, in this respect, to something that Wittgenstein said to Rhees: "The way in which some reality corresponds - or conflicts - with a physical theory has no counterpart here [in ethics]." ${ }^{6}$ Nevertheless, Brandhorst claims that, "There is a kind of correspondence in the case of ethics, too. The notion of correspondence applies, but it must not be confused with the kind of correspondence that we find in physics [...]"7 Brandhorst further aims to explain in what sense we can speak of truth, facts, correspondence and reality in ethics. The "important question" is how these notions are to be understood in ethics. ${ }^{8}$

(ii) No view from nowhere. There is "no view from nowhere in fundamental ethical orientation". ${ }^{9}$ Suppose that we ask which ethical outlook, a Christian one or a Nietzschean one, is right or true. Such a question can only be answered "given our ethical outlook, in the light of our attitudes and commitments" and "there is no such thing as 'the ethical truth' independently of our ethical outlook". ${ }^{10}$ There is "no hope of transcending our personal ethical outlook by means of an appeal to the idea of ethical truth". ${ }^{11}$ There is no such thing as transcending our personal ethical standpoint or orientation, as leaving it behind in order to assess, in an ethically neutral way, which outlook is right or true. To say that, for example, a Christian ethics is true means adopting it, or expressing a particular ethical stance. ${ }^{12}$ It is an illusion to think that we can divide ethical outlooks into true and false without adopting such a stance. That does not

\footnotetext{
${ }^{3}$ In this respect, Brandhorst refers to Wittgenstein (1977: III-311f.).

${ }^{4}$ Brandhorst (2015), 231. See also ibid., 233 ("what it is for such an expression to be true or false can be very different from case to case").

${ }^{5}$ Ibid., 228. See also ibid., 234 ("in an entirely different way") and 241 ("a different idea of 'a correspondence' or 'responsibility' to 'a reality"').

${ }^{6}$ Rhees (1965: 24).

${ }^{7}$ Brandhorst (2015: 236).

${ }^{8}$ Ibid., 241.

${ }^{9}$ Ibid., 231.

${ }^{10}$ Ibid. 231 and 246.

${ }^{11}$ Ibid., 246.

12 Ibid., 234 and 233.
} 
This is the preprint version of an article published in Philosophical Investigations 40 (1), 4063. The final publication is available at Wiley Online: http://onlinelibrary.wiley.com/doi/10.1111/phin.12129/abstract. Please cite the published version only.

mean, however, that there is no room for saying that a particular ethical outlook is true. It only means that saying that a particular outlook is true does not involve any reference to an impersonal, ethically neutral standard.

(iii) There is a language-game in which the expression has a use. According to Brandhorst, 'there is a language-game [...] making use of the words 'right' and 'wrong', 'true' and 'false' [...], and [...] it allows us to pass judgement on a given piece of advice or an ethical outlook. This includes judgements concerning the choice between a 'Christian' or a 'Nietzschean' attitude to marriage [...] So there is a use for 'true' and 'false' even with respect to the highly general question of whether the Christian or Nietzschean ethical outlook is right". ${ }^{13}$ There is "good use" for an expression such as "although I believe that so and so is good, I may be wrong". ${ }^{14}$ Brandhorst adds that "we find it natural, even inevitable, to think of answers to fundamental ethics questions as true and of others as false". ${ }^{15}$ It would be misleading to deny that answers to ethical questions can be true or false or to say that no reality corresponds to ethical expressions, because that would make their use "seem arbitrary in a way in which it is clearly not". ${ }^{16}$ We have a use for these words that is not arbitrary, but "firmly woven into the tapestry of our lives". ${ }^{17}$ To say that no reality corresponds to ethical expressions would make ethical language into "a game played merely for entertainment". ${ }^{18}$

(iv) A deflationary conception, no metaphysical depth. Wittgenstein's conception of truth is deflationary: " $p$ is true" means simply " $p$ ". Such a deflationary conception does not "by itself rule out the idea that ethical truth may involve something more substantial", but it leaves room for the idea that ethical truth may not involve something more substantial, because the idea that an ethical judgement may justly be called true or false even if nothing more substantial is involved. ${ }^{19}$ Talk of truth has no metaphysical depth. ${ }^{20}$

\footnotetext{
${ }^{13}$ Ibid., 231.

14 Ibid., 233.

15 Ibid., 231.

${ }^{16}$ Ibid., 243. Brandhorst uses these words in a discussion of mathematical expressions. As we shall see in (vi), he thinks that his suggestions with respect to truth, etc. in mathematical expressions naturally extend to ethics.

17 Ibid., 243.

18 Ibid., 244.

${ }^{19}$ Ibid., 231.

${ }^{20}$ Ibid., 232.
} 
This is the preprint version of an article published in Philosophical Investigations 40 (1), 4063. The final publication is available at Wiley Online: http://onlinelibrary.wiley.com/doi/10.1111/phin.12129/abstract. Please cite the published version only.

(v) With a certain conception of $x$, we also obtain a conception of a related notion $y$. Brandhorst defends a deflationary conception of truth and claims that "with this conception of ethical truth, we also obtain a conception of ethical facts. Instead of saying that $p$ is true, we can also say that it is a fact that $p$; the concepts "truth" and "fact" were made for each other". ${ }^{21}$ If we can understand "truth" in a deflationary way, then we can understand a related notion such as "fact" in a deflationary way as well. If talk of truth has no metaphysical depth, then talk of facts has no metaphysical depth either. This suggests "a particular way of understanding the uses of 'true' and 'false', 'right' and 'wrong', and related notions [my italics] in the context of ethical language". 22

(vi) The analogy to logic and mathematics. Brandhorst sees important analogies between Wittgenstein's talk of truth, facts, correspondence and reality in logic and mathematics on the one hand and his understanding of these notions in ethics on the other hand. According to his view, Wittgenstein's suggestions regarding truth, etc. in logic and mathematics naturally extend to ethics. ${ }^{23}$ In logic and mathematics, as in ethics, it is "not at all obvious how [...] language relates to reality, and to what reality it could be said to relate". ${ }^{24}$ In both cases, we run into difficulties when we understand truth, etc. as we understand them in physics. ${ }^{25}$ Brandhorst shows how Wittgenstein objects to G. H. Hardy's Platonist understanding of mathematics, in which there is a close analogy between physics and mathematics. Physics and mathematics are far more different than Hardy thought. Again, that does not mean that we cannot talk about truth, facts, reality and correspondence in mathematics. According to Brandhorst, Wittgenstein gradually softened his initial resistance to the idea that there are logical or mathematical facts. ${ }^{26}$ According to Wittgenstein's later views, logical and mathematical expressions such as " $2+2$ $=4$ " "can be used to express a proposition, and propositions can be either true or false". ${ }^{27}$ Wittgenstein does not deny that logical and mathematical statements correspond to reality, but asks "over and over again what 'correspondence to reality' might mean in a logical or mathematical context". ${ }^{28}$ It emerges that "there is a sense in which it is perfectly true and

\footnotetext{
${ }^{21}$ Ibid., 232.

${ }^{22}$ Ibid., 233-234.

${ }^{23}$ Ibid., 242.

${ }^{24}$ Ibid., 237-238.

${ }^{25}$ Ibid., 241.

${ }^{26}$ Ibid., 233.

${ }^{27}$ Ibid., 233.

${ }^{28}$ Ibid., 238; see also ibid., 241.
} 
This is the preprint version of an article published in Philosophical Investigations 40 (1), 4063. The final publication is available at Wiley Online: http://onlinelibrary.wiley.com/doi/10.1111/phin.12129/abstract. Please cite the published version only.

important that something real corresponds to our logical and mathematical language. It also emerges, however, that this reality is not what a Platonist might expect". ${ }^{29}$ Brandhorst explains how, according to Wittgenstein, a reality can be said to correspond to logical and mathematical expressions (in a non-trivial way, that is, not in a way in which we simply translate "it is true" into "a reality corresponds to"). A reality corresponds to logical and mathematical expressions not in the way that it corresponds to propositions like "it rains", but rather in the way that a reality corresponds to words like "two" and "perhaps". ${ }^{30}$

\section{Arguments for Objectivity?}

Based on the outline in the previous section, I will argue in this section that considerations, reasons and arguments similar to those that Brandhorst uses in order to make a case for truth, facts, reality and correspondence in Wittgenstein's thought about ethics can also be used and have been used (with or without explicit reference to Wittgenstein) to make a case for objectivity in ethics. The authors I will mention do not all defend the same conception of objectivity, and it is not my aim to defend or discuss these conceptions in depth. Rather, by referring to different accounts of objectivity that make use of Brandhorst's Wittgensteinian arguments, I want to show that it is plausible that these arguments are all compatible with (different conceptions of) objectivity in ethics, and that some of them clearly point in the direction of an argument for objectivity rather than against it.

(i) In a different way, different kinds, in a different sense. We can acknowledge that we cannot speak of objectivity in ethics in the same way in which we speak of it in, for example, physics. But that does not mean that we cannot speak of objectivity in ethics at all. What it is for something to be objective can be very different from case to case, and we can distinguish between different kinds or ideas or senses of objectivity. ${ }^{31}$ Why not say that there is a kind of objectivity in ethics and that this notion must not be confused with the kind of objectivity that

\footnotetext{
${ }^{29}$ Ibid., 241.

${ }^{30}$ Ibid., 243.

${ }^{31}$ See, for example, distinctions made by Fisher and Kirchin (2006: 14) and Kirchin (2012: 25).
} 
This is the preprint version of an article published in Philosophical Investigations 40 (1), 4063. The final publication is available at Wiley Online: http://onlinelibrary.wiley.com/doi/10.1111/phin.12129/abstract. Please cite the published version only.

we find in physics? The important question, then, will be how objectivity is to be understood in ethics.

(ii) No view from nowhere. Objectivity, in ethics and elsewhere, need not imply that there is a view from nowhere. That is, there is no requirement that, in order to be objective in ethics, we have to (try to) see things independently of our ethical outlook, to transcend our personal standpoint, to abstract from our attitudes and commitments. Being objective does not amount to being ethically neutral. To say that something is objective in ethics may well be to express a particular ethical stance. It does not need to involve any reference to an impersonal, ethically neutral standard.

Such a conception of ethical objectivity is not far-fetched. It has been argued in other domains that objectivity is not threatened by the impossibility of a transcendent perspective, of abstracting from a personal standpoint, from personal reactions, feelings and responses. In the context of a discussion about pain and the contemporary philosophy of mind, Roger Teichmann argues that "in many cases, the foundations of objectivity reside in those very reactions and responses that get too easily classified as "merely subjective". ${ }^{32}$ According to Raimond Gaita, "to say that it is a requirement of objectivity that we step back to the point where we see human beings as merely amongst the many possible entities that can think, feel, etc., and that a human perspective is only one (limited) epistemic vantage point inferior to 'the point of view of the universe', is a classical philosophical instance of sawing away the branch on which one is sitting". ${ }^{33} \mathrm{He}$ criticises the "illegitimate insistence that objective thought must always be separable from feeling". ${ }^{34}$ An objective judgement is not one that is uninformed by feeling or personal attitudes or commitments or outlooks, but one which is undistorted by them. ${ }^{35}$ Christopher Leich and Steven Holtzman claim that Wittgenstein stresses "the anthropocentric nature of even our most objective practices of understanding, such as mathematics". ${ }^{36}$ They

\footnotetext{
32 Teichmann (2001: 35).

33 Gaita (2004: 168).

${ }^{34}$ Gaita (2000: 89). See also Ripstein (1993: 359): the problem for objectivity is not that moral judgements always depend in many ways on personal standpoints, characteristics, reactions, etc., but that they sometimes inappropriately depend on them.

35 Gaita (2000: 89).

${ }^{36}$ Leich and Holtzman (1981: 21). See also Wiggins (1998: 101): “[...] a matter that is anthropocentric may be either more objective or less objective, or (at the limit) merely subjective". Lovibond (1983: 40) quotes Pears (1971: 171,) who ascribes to Wittgenstein the idea that "objectivism, in its only tenable form, collapses into anthropocentrism".
} 
This is the preprint version of an article published in Philosophical Investigations 40 (1), 4063. The final publication is available at Wiley Online: http://onlinelibrary.wiley.com/doi/10.1111/phin.12129/abstract. Please cite the published version only.

explicitly state that "the moral objectivist need not [...] violate Wittgenstein's insights. He can maintain that moral assessments do express personal attitudes, and hence stand in an internal relation to action, while maintaining that they make a further cognitive claim." ${ }^{37}$ And Alice Crary, defending "a conception of objectivity no longer governed by an abstraction requirement", 38 maintains that our rejection of the idea of a view from nowhere "has no implications for our claim to basic epistemic ideals like objectivity". ${ }^{39}$ She presents and defends an account of moral concepts "as determining features of the world that, while they need to be understood in terms of our attitudes, are nevertheless fully objective [...] What thus emerges is that here moral concepts trace out objectively consistent patterns, not [...] in a neutrally available region of fact, but rather in the moral outlooks within which they function". ${ }^{40}$ She refers, in this context, to the work of Stanley Cavell, Cora Diamond, Sabina Lovibond, John McDowell, Iris Murdoch and David Wiggins.

(iii) There is a language-game in which the expression has a use. Is there any use for talk of objectivity in ethics? It is probably less pervasive, at least in ordinary language, than talk about truth or reality, but that holds for "correspondence" as well. It certainly allows us (if "true" and "right" do, as Brandhorst claims) to pass judgement on a given piece of advice or a certain ethical outlook. There seems to be good use for such expressions as "although I believe that so and so is good, it may not be objectively good" or "although it appears to be good, it may not be objectively/really good" (on this point, see my comments on Brandhorst's reading of Wittgenstein in section V). ${ }^{41}$ Whether we find it natural or inevitable to use "objective" in ethical contexts can be discussed, but the same holds for correspondence and reality. In any case, if it is misleading to deny that answers to ethical questions can be true or false or to say that no reality corresponds to ethical expressions, because that would make their use seem arbitrary in a way in which it is clearly not, it seems at least equally misleading to deny that there is objectivity in ethics or to say that ethics is subjective. To say that something is subjective may suggest that it is "a matter of whim or arbitrary decision, discretionary or

\footnotetext{
${ }^{37}$ Leich and Holtzman (1981: 17).

${ }^{38}$ Crary (2007b: 308).

${ }^{39}$ Crary (2007a: 4). See also Crary (2007b: 307).

${ }^{40}$ Crary (2007c: 37-38). See Crary (2007c: esp. chapters 1 and 2) for a full-blown defence of this point.

${ }^{41}$ Leich and Holtzman claim that "Objectivity, on one well-established use of the term, is located in the distinction between appearance and reality; to maintain that it is an objective matter whether or not a certain speaker's claim is true is, on this use, to maintain that there is a clear difference between the claim's merely seeming to be true to the speaker and its actually being true" (1981:2).
} 
This is the preprint version of an article published in Philosophical Investigations 40 (1), 4063. The final publication is available at Wiley Online: http://onlinelibrary.wiley.com/doi/10.1111/phin.12129/abstract. Please cite the published version only.

unimportant", ${ }^{42}$ as if we could decide what is ethically good. Arthur Ripstein delimits objectivity negatively, "in terms of the absence of inappropriate factors" and "by its contrast with some particular account of bias". ${ }^{43}$ In the light of his deflationary conception of objectivity, to say that a judgement is subjective is to say that certain inappropriate factors have influenced it, or that it is biased. "To call a judgment subjective is either to disparage it openly, or else to politely suggest its irrelevance to justification." ${ }^{44}$ If, then, one attributes to Wittgenstein the idea that ethics is essentially subjective, as Brandhorst does, one can easily be taken to suggest that something inherently inappropriate or biased is involved in all ethical judgement-making. That is certainly not what Wittgenstein, early or late, said or wanted to say.

(iv) A deflationary conception, no metaphysical depth. A conception of objectivity in ethics can be deflationary in the sense that it leaves room for the idea that objectivity may not involve "something more substantial". Talk of objectivity need not have any metaphysical depth. Ripstein has developed a deflationary account of objectivity, "faithful to the contexts in which the concept of objectivity is useful", ${ }^{45}$ and he claims that his is "the only idea of objectivity that we need (Or arguably, that we ever really had anyway, except for loaded uses in partisan philosophical debates.)". ${ }^{46}$ According to his account, objectivity is not a property and a belief is objective if it satisfies a metaphysically innocent independence condition: in order for a belief to be objective, the fact that I think it must not make it so. ${ }^{47}$ According to Paul Johnston, "the real objectivity question in ethics is whether we accept the claim that there are ways of acting that everyone should recognise as correct. Holding this belief, however, does not involve any specific claims about the nature of what exists." 48 Crary deplores the assumption that, if we attempted to accommodate objective and intrinsically practical features of the world, "we could not help but take for granted a category of metaphysically odd (or unnatural qualities)". ${ }^{49}$

\footnotetext{
42 Baker and Hacker (2009: 338). Wittgenstein seems to link the objective to what we cannot decide in (1975: $\S \S 270-271)$.

${ }^{43}$ Ripstein (1993: 359 and 361).

${ }^{44}$ Ibid., 370.

45 Ibid., 356.

46 Ibid., 361.

${ }^{47}$ Ibid., 360 and 358.

${ }^{48}$ Johnston (1999: 117). See, on this issue, Johnston (1999: chapter 5) and (1989: chapter 7).

${ }^{49}$ Crary (2007b: 302-303).
} 
This is the preprint version of an article published in Philosophical Investigations 40 (1), 4063. The final publication is available at Wiley Online: http://onlinelibrary.wiley.com/doi/10.1111/phin.12129/abstract. Please cite the published version only.

Andrew Fisher and Simon Kirchin write that talk of objectivity need not commit us "to any one particular ontological account". 50

(v) With a certain conception of $x$, we also obtain a conception of a related notion $y$. Although the idea of a related notion is pretty elastic, "objectivity" seems to qualify in a rather uncontroversial way as a notion related to "truth", "fact", "correspondence" and "reality". Diamond, for instance, clearly recognises this. She quotes Wittgenstein, who says that the words "subjective" and "objective" "point to a difference between language-games",51 and adds: "But, we may wish to say, it is not simply a matter of a difference of language-games, but of whether there can be truth and falsity in a particular language-game." 52 According to David Wiggins, "a subject matter is objective if and only if enough of the questions that are posed within it admit of answers that are substantially true - simply and plainly true, that is". ${ }^{53}$ Fisher and Kirchin write that "when we say that a given area of thought or discourse [...] is objective we might well mean that [...] judgements typically made within the area are truth-apt".54 Kirchin characterises a sense of objectivity in which something is objective "if it consistently features in the experiences of typical, mature human beings and whose reality [my italics] is hard to ignore". 55 Another notion related to "truth", "reality", etc. is "knowledge". Brandhorst writes: "if there are truths [and, as we have seen, Brandhorst thinks that there are ethical truths, if only in some particular sense], there are facts, and with truths and facts there can be doubt, belief and knowledge". ${ }^{56}$ So, according to Brandhorst's Wittgenstein, there can be ethical knowledge, and Wittgenstein himself seems to acknowledge the link between knowledge and objectivity: "It would be correct to say: 'I believe ...' has subjective truth; 'I know ...' not."

Thus, a deflationary conception of objectivity without metaphysical depth is not only, as it were, independently plausible in the light of Wittgenstein's later philosophy, but the need for such a conception becomes even more pressing when "truth", "fact", "reality", "knowledge"

\footnotetext{
${ }^{50}$ Fisher and Kirchin (2006: 14).

${ }^{51}$ Wittgenstein (2009b: $\left.\$ 340\right)$.

52 Diamond (1991: 238).

${ }^{53}$ Wiggins (2006b: 359).

${ }^{54}$ Fisher and Kirchin (2006: 14). For another link between objectivity, truth and correspondence, see Ripstein (1993: 360-361).

${ }^{55}$ Kirchin (2012: 132).

${ }^{56}$ Brandhorst (2015: 233).

${ }^{57}$ Wittgenstein (1975: §179). For a link between truth, knowledge and objectivity, see also Lovibond (2002: 15 16).
} 
This is the preprint version of an article published in Philosophical Investigations 40 (1), 4063. The final publication is available at Wiley Online: http://onlinelibrary.wiley.com/doi/10.1111/phin.12129/abstract. Please cite the published version only.

and "correspondence" are already understood in a deflationary, non-metaphysical way. A deflationary understanding of the latter notions invites a similar understanding of objectivity. Hence, Brandhorst's arguments do not just leave room for (allow for, are compatible with) a Wittgensteinian conception of objectivity or make such a conception possible. They actually contribute to the case for such a conception.

(vi) The analogy to logic and mathematics. If Wittgenstein's suggestions regarding truth, reality, etc. in logic and mathematics naturally extend to ethics, there is no reason to assume that things would have to be otherwise regarding objectivity. While we will certainly run into difficulties if we understand objectivity in mathematics as we understand it in physics, this should not prevent us from talking about objectivity in mathematics. Nowhere does Wittgenstein deny that there is objectivity in mathematics. ${ }^{58}$ Rather, he shows that mathematics is not objective in the way that a Platonist might expect, because "mastery of mathematics depends on our possession of a complex cluster of attitudes - senses of what is important, relevant, even senses of what constitutes a good reason for drawing a particular inference". 59 Wittgenstein's philosophy of mathematics brings out that mathematics and ethics are more similar in certain respects than we tend to think and suggests that objectivity is one of these respects. ${ }^{60}$ Wiggins remarks that, "for someone who wanted to combine objectivity [in ethics] with a doctrine of qualified cognitivism or of underdetermination, there might be no better model than Wittgenstein's normative conception of the objectivity of mathematics; and no better exemplar than Wittgenstein's extended description of how a continuing cumulative process of making or constructing can amount to the creation of a shared form of life that is constitutive of rationality itself $[\ldots] "{ }^{61}$ Moreover, Wiggins believes that the resulting

\footnotetext{
${ }^{58}$ Although some commentators have read him as if he did. Crispin Wright (1980) is an example. For a good discussion of Wright's Wittgenstein and objectivity in logic and mathematics, see Diamond (1991a). Diamond shows that Wittgenstein's later philosophy of logic and mathematics is "distorted if seen in anti-realist terms, and does not involve the denials of objectivity Wright sees" (1991a: 217). Another example of a commentator who reads Wittgenstein as if he denied that there is objectivity in logic and mathematics is Michael Dummett (1959). In (1991c), Diamond discusses "the impression, given to Dummett and others, that Wittgenstein denies the objectivity of proof. It looks as if Wittgenstein is saying that it is all really subjective, after all, only what characterises it is that we say it is not. But Wittgenstein is not denying that there is all the difference between what is really an objectively valid proof and one which only appears valid" (1991c: 256). See, in this respect, Wittgenstein (2009b: §348) and Baker and Hacker (2009: 297).

${ }^{59}$ Leich and Holtzman (1981: 21).

${ }^{60}$ Disagreement is another. See Leich and Holtzman (1981: 21) on Wittgenstein's famous example of the woodsellers.

${ }^{61}$ Wiggins (1998: 128). See also Wiggins (2006a: 330 and 2006b: 366-367).
} 
This is the preprint version of an article published in Philosophical Investigations 40 (1), 4063. The final publication is available at Wiley Online: http://onlinelibrary.wiley.com/doi/10.1111/phin.12129/abstract. Please cite the published version only.

conception of objectivity in ethics will be harmonious with "the rough and ready ordinary acceptation of the word". 62

In the light of Brandhorst's arguments and Wittgenstein's philosophy of mathematics, it would be misleading to deny that mathematics is objective, because it would make the use of mathematical expressions seem arbitrary in a way that they are clearly not. Brandhorst's suggestion to understand Wittgensteinian ethics according to the model of Wittgenstein's understanding of mathematics does not just make it possible to talk about objectivity in ethics in a way similar to the way in which it is possible to talk about objectivity in mathematics. It actually contributes to the case for objectivity in ethics because it is much less controversial to say that there is objectivity in mathematics than to say that there is objectivity in ethics. A Wittgensteinian approach to objectivity in mathematics and in ethics would involve asking over and over again what "objectivity" might mean in mathematical and ethical contexts, and it would emerge that these kinds of objectivity are not what a Platonist might expect.

\section{Brandhorst's Conception of Objectivity}

If Brandhorst's own Wittgensteinian considerations, reasons and arguments in defence of truth, etc. in ethics allow, prima facie (that is, on the basis of my brief outline of these arguments), for objectivity in ethics and if they have indeed been frequently used to make a case for objectivity in ethics, then why does Brandhorst think that objectivity is Wittgenstein's real target ${ }^{63}$ I will argue that it is because his conception of objectivity in ethics is distorted by a

\footnotetext{
${ }^{62}$ Wiggins (2006b: 370).

${ }^{63}$ According to Brandhorst, another target of Wittgenstein is realism (2015: 21). In the light of Brandhorst's own arguments, this is a strange claim. Does he not ascribe a form of realism to Wittgenstein when he says that, according to Wittgenstein, a reality corresponds to ethical expressions? Brandhorst seems to think that we can only speak of realism when the reality that we appeal to is of a particular kind, more specifically the kind of reality that corresponds to expressions in physical theory. He says that realism is Wittgenstein's target because "claims to truth and objectivity that are the hallmark of the realist perspective cannot be maintained" (ibid.: 21). In this article, I argue that claims to objectivity can be maintained, if only in a particular sense. But that just means that the realism we can ascribe to Wittgenstein in the light of Brandhorst's arguments will be a particular kind of realism, not that realism as such (rather than Platonist forms of it) was his target, as Brandhorst claims. With respect to truth, Brandhorst seems to think that realists cannot understand truth as Wittgenstein understands it. But that is not true. As Brandhorst himself acknowledges early in his article, a Wittgensteinian deflationary conception of truth "does not by itself rule out the idea that there is an objective reality of one kind of another [my italics] to which a given true proposition corresponds" (ibid.: 6). A deflationary conception of truth is perfectly compatible with realism.
} 
This is the preprint version of an article published in Philosophical Investigations 40 (1), 4063. The final publication is available at Wiley Online: http://onlinelibrary.wiley.com/doi/10.1111/phin.12129/abstract. Please cite the published version only.

Platonist picture that is similar to the picture that he explicitly warns about in talking about truth, facts, reality and correspondence in ethics.

(1) Firstly, Brandhorst sees a necessary link between the objective on the one hand and the impersonal and the neutral on the other. When he discusses ethical truth, he rightly emphasises that Wittgenstein does not leave room for the idea of a view from nowhere. Ethical questions can only be answered in the light of our ethical outlook, our attitudes and commitments. There is no such thing as transcending our personal ethical standpoint in order to assess, in an ethically neutral way, whether an ethical outlook or judgement is right or true. But Brandhorst does not just dismiss the idea of impersonal or neutral ethical truth. Instead, he dismisses "the idea of objective, impersonal truth". ${ }^{64}$ In his view, there cannot be room for objectivity in ethics because there is no room for impersonal and neutral ethical truth. That does not follow, however, if a conception of objectivity as outlined in III, (ii) that is faithful to the contexts in which we use the concept can be developed.

Brandhorst concludes that, for Wittgenstein, "ethics remains deeply personal. It is bound up with the deepest concerns and commitments of those who see the world around them from a singular, ethical point of view." ${ }^{65} \mathrm{He}$ adds that "in this respect, there is a surprisingly deep continuity between the later work and the Tractatus. Regardless of its ties to a social world, ethics is essentially subjective. It is bound to a particular perspective, a point of view towards the world. ${ }^{" 66}$ It is certainly true that Wittgenstein, both early and late, saw ethics as deeply personal and bound up with people's deepest concerns and commitments. It does not follow, though, that he saw ethics as essentially subjective. That only follows if what is deeply personal and bound up with people's deepest concerns and commitments cannot be objective. ${ }^{67}$ It follows if one adheres to a conception of objectivity in which objectivity requires the possibility of a view from nowhere. It is remarkable that, while Brandhorst rightly objects to Platonist viewfrom-nowhere accounts of truth, facts, correspondence and reality, he implicitly commits himself to such a view-from-nowhere account of objectivity. He succumbs, in my view, to a temptation described by Wittgenstein in The Blue Book: "When we look at everything that we know and can say about the world as resting upon personal experience, then what we know

\footnotetext{
${ }^{64}$ Ibid., 231.

${ }^{65}$ Ibid., 245-246.

${ }^{66}$ Ibid., 246.

${ }^{67}$ And, one should add, if what is not objective is thereby subjective. That may seem obvious, and it is clearly obvious for Brandhorst, but see Wiggins (2006b: 377).
} 
This is the preprint version of an article published in Philosophical Investigations 40 (1), 4063. The final publication is available at Wiley Online: http://onlinelibrary.wiley.com/doi/10.1111/phin.12129/abstract. Please cite the published version only.

seems to lose a good deal of its value, reliability, and solidity. We are then inclined to say that it is all 'subjective' [...] This should remind us of the case when the popular scientist appeared to have shown us that the floor which we stand on is not really solid because it is made up of electrons." ${ }^{68}$ Just as the fact that the floor is made up of electrons should not, in Wittgenstein's view, prevent us from saying that it is solid, although popular scientists are inclined to say that it is not really solid, the fact that we cannot transcend our personal standpoint in ethics should not prevent us from saying that some ethical judgements are objective, although some ethicists are inclined to say that they are all subjective. Just as some popular scientists misunderstand what it means to say, in everyday language, that something is solid, and confuse it with the meaning of solidity in specialised, scientific accounts, Brandhorst seems to misunderstand what it means to say, in everyday ethical language, that something is objective, and confuses it with the meaning of objectivity in a Platonist view-from-nowhere account.

As Brandhorst notes in the beginning of his article, the later Wittgenstein "abandoned his Tractarian conception of reality, language and representation. Without that conception, the claim that 'ethics cannot be expressed' lacked its former rationale; and in the light of the later conception of language that slowly emerged, it is hard to see what a new rationale could be". ${ }^{69}$ Brandhorst would admit that the conception of reality, language and representation outlined in the Tractatus is a view-from-nowhere account and that, with regard to objectivity too, we cannot expect anything but a view-from-nowhere account from the Tractatus. According to such an account, there are no ethical truths or ethical facts and there is no correspondence between ethical language and ethical reality. Similarly, according to such an account, there is no objectivity in ethics. We can agree with Brandhorst here and say that the early Wittgenstein saw ethics as essentially subjective. ${ }^{70}$ But without a Tractarian view-from-nowhere account of objectivity, that claim lacks its former rationale. Why would Wittgenstein have abandoned his conceptions of reality, language and representation while keeping his conception of objectivity intact? Is a Tractarian conception of objectivity not as untenable as Tractarian conceptions of reality, language and representation, and for largely the same reasons? The later Wittgenstein

\footnotetext{
${ }^{68}$ Wittgenstein (1969: 48).

${ }^{69}$ Brandhorst (2015: 227-228).

${ }^{70}$ Although it is more accurate, within a Tractarian framework, to say that it makes no sense to speak of ethical truths or facts or objectivity in ethics or correspondence of ethical language with an ethical reality. It does not follow from "it makes no sense to say that ethics is objective" that "ethics is subjective" or that "ethics is essentially subjective". What follows is that it makes no sense to say that ethics is subjective either. For the sake of the argument, however, I grant that Brandhorst is right in saying that, for the early Wittgenstein, ethics is subjective.
} 
This is the preprint version of an article published in Philosophical Investigations 40 (1), 4063. The final publication is available at Wiley Online: http://onlinelibrary.wiley.com/doi/10.1111/phin.12129/abstract. Please cite the published version only.

gives us no reason to suppose that, in order to be objective, we have to abstract from our personal commitments and occupy some kind of Archimedean point of view, since there is no such point of view to occupy. Objectivity does not have to be understood as incompatible with the expression of personal commitments. The fact that we cannot abstract from the latter gives us no reason to claim that Wittgenstein still saw ethics as essentially subjective. Indeed, according to a view of objectivity purged from Tractarian misconceptions, Wittgenstein's rejection of the Hamletian thought that "nothing is either good nor bad, but thinking makes it so" could be enough to justify talk of objectivity in ethics (on this point, see the striking similarity between the formulations of Wittgenstein's rejection of the Hamletian thought and Ripstein's deflationary account of objectivity in III, (iv))..$^{71}$ Thus, the continuity that Brandhorst sees between the later work and the Tractatus is not as deep as he suggests. Ethics remains deeply personal, but the later Wittgenstein is not committed to the claim that it is essentially subjective.

(2) Brandhorst's conception of objectivity in ethics is distorted by a picture he warns against in talking about truth, etc. in a second way. He writes: "So Wittgenstein also accepts the idea that an ethical judgement may justly be called true or false. Moreover, he accepts it in a sense that goes beyond a 'relative' sense that merely fits a given ethical judgement into a given ethical outlook, using standards of coherence. But as it stands, this concession is worthless for the objectivist. He wants - and needs - something more substantial than that."72 And: "All the same, if there are truths, there are facts, and with truth and facts there can be doubt, belief and knowledge. But as before, these concessions have no metaphysical depth. So by themselves, they cannot give objectivists what they require." ${ }^{\prime 73}$ Apparently, the objectivist wants and needs "something more substantial", something Brandhorst (and Wittgenstein) cannot give him: metaphysical depth. If the objectivist is simply someone who believes that there is objectivity in ethics, then this is a remarkable claim. ${ }^{74}$ Brandhorst does not argue for

\footnotetext{
${ }^{71}$ Wittgenstein (2014: 45).

72 Brandhorst (2015: 232).

${ }^{73}$ Ibid., 233. See also ibid., 245 (“[...] a 'quality' as the objectivist conceives of it”).

${ }^{74}$ One could object here that Brandhorst maybe sees the objectivist not simply as someone who believes that there is objectivity in ethics, but rather as someone who believes that there is a particular kind of objectivity in ethics, more specifically the kind of objectivity that we find in physics. In that case, the belief that there is objectivity in ethics would not make one an ethical objectivist, as the belief that ethical expressions correspond to a reality does not make one an ethical realist in Brandhorst's view (see footnote 63), and the objectivist would indeed require "something more substantial". However, if this were the reading that Brandhorst favours, then what he says about the objectivist could not support his case, on behalf of Wittgenstein, against claims to objectivity in ethics. At most, it could support a case against a kind of Platonist objectivism. However, Brandhorst makes it clear that he
} 
This is the preprint version of an article published in Philosophical Investigations 40 (1), 4063. The final publication is available at Wiley Online: http://onlinelibrary.wiley.com/doi/10.1111/phin.12129/abstract. Please cite the published version only.

this claim, he simply asserts that the objectivist needs something more substantial. But that is not true if a deflationary account of objectivity as outlined in III, (iv) which is faithful to the contexts in which we use the concept can be developed. Such a conception is invited by Brandhorst's own arguments, on behalf of Wittgenstein, for truth, facts, correspondence and reality in ethics. Brandhorst takes pains to argue that truth, etc. do not require metaphysical depth and that these notions will mislead us if we "superimpose [...] Platonist pictures" ${ }^{75}$ But he overlooks the fact that the same may be true, for largely similar reasons, of objectivity.

\section{How Brandhorst Reads Wittgenstein on Objectivity}

I have argued that Brandhorst's considerations, reasons and arguments invite, rather than resist, the idea of objectivity in Wittgensteinian ethics, but that Brandhorst cannot see this because he is wedded to a conception of objectivity of a Platonist kind, the kind of conception he explicitly warns against in talking about truth, facts, reality and correspondence in ethics. So far, I have ignored the fact that Brandhorst uses some quotations from Wittgenstein in order to support and confirm his position about objectivity in the later Wittgenstein's thought about ethics. ${ }^{76}$ I will argue in this section that, influenced by his view-from-nowhere conception of objectivity, he has misinterpreted these quotations.

I will start with a brief outline of how Brandhorst wants us to read Wittgenstein. His discussion of Wittgenstein's thought about truth, facts, correspondence and reality in ethics leans heavily on his reading of a remark, already quoted in II, (i), in which Wittgenstein says to Rhees that the "way in which some reality corresponds - or conflicts - with a physical theory has no counterpart here [with respect to ethical judgement]". Brandhorst comments on this remark as follows: "When we read his words carefully, Wittgenstein does not seem to want to simply deny that there can be a correspondence between some ethical judgement and some reality." ${ }^{77}$ He makes similar comments later on: "[...] it is not clear that we should simply say that no reality corresponds to ' $2+2=4$ "”; “[...] Wittgenstein does not wish to deny that 'a

\footnotetext{
thinks that Wittgenstein is not just arguing against "overly ambitious forms of Platonism", but that realism and objectivity are his targets, and that that is what he wishes to make plausible (ibid., 21-22).

${ }^{75}$ Ibid., 244.

${ }^{76}$ Ibid., 248.

${ }^{77}$ Ibid., 236.
} 
This is the preprint version of an article published in Philosophical Investigations 40 (1), 4063. The final publication is available at Wiley Online: http://onlinelibrary.wiley.com/doi/10.1111/phin.12129/abstract. Please cite the published version only.

reality corresponds' to logical or mathematical language." $" 78$ And he supports these comments by a quotation from Wittgenstein's Lectures on the Foundations of Mathematics: "I don't say: 'No reality corresponds." "79 He concludes that "The right thing to say is precisely what W says: The way in which a reality corresponds - or conflicts - with a physical theory has no counterpart here. As before, we should not say: 'No reality corresponds'; and as before, W makes a point of not saying it." $" 80$

In short, Brandhorst frequently warns us against the temptation to read Wittgenstein as if he denied something which he only questions or problematises. ${ }^{81}$ The temptation to read Wittgenstein in such ways has been noted, for instance, by Oswald Hanfling. Hanfling sees this temptation as a way of getting into difficulties with Wittgenstein. It is "a craving to look for hard and fast claims where what one is given is tentative investigations; for proofs and refutations where 'description alone' is intended; and for answers where only questions are given". ${ }^{82}$ Brandhorst recognises the danger of such cravings for hard and fast claims, proofs and refutations. He often uses italics to emphasise "deny" and "no". In that way, he makes it clear that we should not ascribe to Wittgenstein the hard and fast claim that no reality corresponds to ethical language and that we should not take him to refute the idea of such a correspondence.

Brandhorst is right in reading Wittgenstein as he does in the context of correspondence and reality; that is, in not reading denials into Wittgenstein. He is less careful, however, and less true to his own hermeneutical maxims, in his treatment of two other passages. (1) In his Philosophical Investigations, Wittgenstein says about objectivity in mathematics that "what a mathematician is inclined to say about the objectivity and reality of mathematical facts is not a philosophy of mathematics, but something for philosophical treatment". ${ }^{83}$ Brandhorst quotes this in a footnote in order to illustrate that Wittgenstein's “therapeutical task is to uncover the various pictures, assumptions and fragments of theory that encourage the Platonist interpretation". ${ }^{84} \mathrm{He}$ does not notice, however, that Wittgenstein not only mentions what the mathematician is inclined to say about reality as a candidate for treatment, but also what he is

\footnotetext{
${ }^{78}$ Ibid., 241 and 244.

${ }^{79}$ Wittgenstein (1976: 249).

${ }^{80}$ Brandhorst (2015: 245).

${ }^{81}$ See also ibid., 235 and 240 (footnote 47 ).

${ }^{82}$ Hanfling (2002: 12).

${ }^{83}$ Wittgenstein (2009a: §254).

${ }^{84}$ Brandhorst (2015: 241).
} 
This is the preprint version of an article published in Philosophical Investigations 40 (1), 4063. The final publication is available at Wiley Online: http://onlinelibrary.wiley.com/doi/10.1111/phin.12129/abstract. Please cite the published version only.

inclined to say about objectivity. For Wittgenstein, objectivity and reality in mathematics very much seem to be in the same boat. One way to read this passage would be to say that Wittgenstein denies that mathematical facts can be real or objective. Such a reading, in which we take Wittgenstein to deny something which he merely questions or problematises, goes against the way in which Brandhorst asks us to read Wittgenstein. Another way to read this passage, the most natural and right way in my view, and the way that aligns with Brandhorst's recommendations, would be to say that Wittgenstein does not deny that mathematical facts can be real or objective. He does not say that there is no reality or no objectivity in mathematics. He merely warns us against a certain way of understanding what "reality" and "objectivity" in a mathematical context amount to. If we understand "reality" and "objectivity" in the way that the Platonist and certain mathematicians understand them, then what we will say about the reality and objectivity of mathematical facts will make no sense, and philosophical treatment will show that. So if we read the passage in the way that Brandhorst recommends that we read Wittgenstein, and if Wittgenstein's suggestions with respect to truth, reality, etc. in mathematics naturally extend to ethics, as Brandhorst claims, we have every reason to suppose that reality and objectivity will be in the same boat there as well. But that is exactly what Brandhorst denies or is at least committed to denying. While he recognises that we can speak of reality in Wittgensteinian ethics, claims to objectivity in ethics are said to be Wittgenstein's target. Thus, Brandhorst's conclusion about objectivity in Wittgensteinian ethics seems to be at odds with his preferred way of reading Wittgenstein.

(2) According to Brandhorst, a passage from Wittgenstein's conversations with Rhees confirms that claims to objectivity in ethics are Wittgenstein's target. Rhees reports: "He [Wittgenstein] came back to this question of 'the right ethics' later. He did so once (in 1945) when he was discussing the relations of ethics and psychology and sociology. 'People have had the notion of an ethical theory - the idea of finding the true nature of goodness or of duty. Plato wanted to do this - to set ethical inquiry in the direction of finding the true nature of goodness - so as to achieve objectivity and avoid relativity. He thought relativity must be avoided at all costs, since it would destroy the imperative in morality." $\$ 85$

This passage from Wittgenstein's conversations with Rhees can only confirm that claims to objectivity in ethics are Wittgenstein's target if Wittgenstein is taken to deny that there

\footnotetext{
${ }^{85}$ Rhees (1965: 23).
} 
This is the preprint version of an article published in Philosophical Investigations 40 (1), 4063. The final publication is available at Wiley Online: http://onlinelibrary.wiley.com/doi/10.1111/phin.12129/abstract. Please cite the published version only.

is objectivity in ethics. But, pace Brandhorst, Wittgenstein does not deny that. What we have here is "description alone", and the temptation or craving to look for hard and fast claims should be avoided. If Brandhorst would have read this passage as he read the passage about there being no counterpart in ethics for the way in which some reality corresponds with a physical theory, he would have emphasised that Wittgenstein does not say that there is no objectivity in ethics. If this passage about Plato and objectivity confirms that Wittgenstein's target was objectivity in ethics, then the passage about physical theory will confirm that Wittgenstein's target was reality in ethics. Brandhorst, however, uses the counterpart passage to defend the idea that there is room for correspondence to reality in ethics, and the passage about Plato to deny that there is room for objectivity in ethics.

If the passage about Plato should not be read as if Wittgenstein denied that there is objectivity in ethics, then how could it be read? Wittgenstein talks about what "people" and "Plato" wanted to do, namely, to find the true nature of goodness or of duty so as to achieve objectivity and avoid relativity. He does not say that this cannot be done or that there is no such thing as objectivity in ethics. Rather, in line with the passage about objectivity in mathematics and his warnings against Platonist pictures, I suggest that he could be read as saying that what people and Plato (and Platonists) are inclined to say about the true nature of goodness or duty, or what they are inclined to say about objectivity in ethics, is something for philosophical treatment. Thus, contrary to what Brandhorst claims, Wittgenstein's target in this passage is Platonism (and people inclined to Platonist talk) rather than objectivity. Once more, the "important question" is how "true nature" and "objectivity" are to be understood.

Brandhorst comments on the passage as follows: "Presumably, to find the 'true nature' of goodness or duty would be to find the criterion by which we could judge what is really good, as opposed to merely apparently good, or good from our point of view. In other words, that criterion would be objective. [...] That search was based on an illusion, and it is a further illusion to think that without objectivity, there can be no imperative in ethics." ${ }^{" 86}$ Brandhorst reads Wittgenstein as if he were saying that there is no place for objective criteria in ethics. He opposes what is really or objectively good to what is apparently good or good from our own point of view. He thinks that because we cannot abstract from our point of view in ethics and because there is no view from nowhere, things cannot be objectively good (remember, in this

\footnotetext{
${ }^{86}$ Brandhorst (2015: 22).
} 
This is the preprint version of an article published in Philosophical Investigations 40 (1), 4063. The final publication is available at Wiley Online: http://onlinelibrary.wiley.com/doi/10.1111/phin.12129/abstract. Please cite the published version only.

regard, the passage from The Blue Book in IV). But that only follows if one adheres to a conception of objectivity as outlined in IV, and not if a Wittgensteinian conception of objectivity as outlined in III, (ii) which is more faithful to the contexts in which we use the concept, can be developed. Neither the search for the true nature of goodness or duty nor the search for objective criteria in ethics are based on illusions, but the idea that objectivity necessarily excludes our personal point of view.

Brandhorst's comment is misleading, moreover, in that it suggests that it does not make sense to talk about "really good" as opposed to "apparently good". But there is good reason for such a contrast. Brandhorst recognises that there is good reason to use the expression "although I believe that so and so is good, I may be wrong" (see also II, (iii)), and he adds that this expression should not be taken to involve "a commitment to ethical truth that transcends any personal standpoint". ${ }^{87}$ Why not say, then, that there is a place for an expression such as "although it appears good to me, it may not be really/objectively good", and add that this expression should not be taken to involve a commitment to ethical reality or objectivity that transcends any personal standpoint? It does not make sense to speak of things being really or objectively good if that means "good from a God's eye point of view", but that does not mean that things or deeds cannot be really good as opposed to being merely apparently so.

Or does it? One could defend Brandhorst as follows. If there is no view from nowhere, if we cannot transcend our personal standpoint in ethics, then "it is good" can only mean "it is good from my point of view". And is that not exactly what "it appears to be good" means? Does the distinction between "it is good" and "it appears to be good" not collapse when it becomes a distinction between "it is good (from my point of view)" and "it appears to be good"? The answer is no. An analogy may help to illustrate this. Suppose that we are asked what colour something is and that we are not allowed to use scientific instruments in order to measure wavelengths, etc. We cannot occupy a view from nowhere in order to look at the object; we only have our own personal standpoint. We say that the object is red. Here, "it is red" is not equivalent to "it appears to be red", because the latter expression suggests that we are not sure. We would use it, for example, when it is dark, when we think that our eyes may not be functioning well or when the distance between us and the object does not allow us to make out its colour; in short, when circumstances are such that we would not sincerely claim to know that

\footnotetext{
${ }^{87}$ Ibid., 233.
} 
This is the preprint version of an article published in Philosophical Investigations 40 (1), 4063. The final publication is available at Wiley Online: http://onlinelibrary.wiley.com/doi/10.1111/phin.12129/abstract. Please cite the published version only.

it is red. If we know that something is red (and it seems obvious that we can justly be said to know that some things are red even if we cannot transcend our personal standpoint), we usually do not say that it appears red to us. The latter may not be wrong, but it would at least be misleading. ${ }^{88}$ Similarly, if we (think that we) know that something is good, we usually do not say that it appears good to us, for that would be misleading too. As we have seen, Brandhorst recognises that the later Wittgenstein's thought allows for ethical knowledge, and Wittgenstein links knowledge to objectivity. The ethical knowledge Wittgenstein allows for does not require a view from nowhere, because, as Brandhorst rightly stresses, there can be no such thing in Wittgensteinian ethics. It is knowledge "from my point of view". Now if there is such ethical knowledge and if "appear" suggests (maybe not always, but at least sometimes) that we do not know, then the distinction between "it is good" and "it appears to be good" does not collapse: it will often be possible to read it as a distinction between "I know (from my point of view) that it is good" and "it appears (from my point of view) to be good, but I am not sure, I may be wrong, mistaken, etc.”

In summary, we can say that Brandhorst has misread the passage that he thinks confirms that claims to objectivity in ethics are Wittgenstein's target. Going against his own recommendations for reading Wittgenstein, he reads the passage as if Wittgenstein denied that there is a meaningful contrast between what is really good and what is apparently good, and as if he denied that there is objectivity in ethics. The reason why Brandhorst misreads Wittgenstein lies in his conception of objectivity, a conception that links the possibility of objectivity to the possibility of a view from nowhere.

\section{Conclusion}

I conclude that Brandhorst has not provided convincing reasons or arguments for his conclusion that Wittgenstein's target is objectivity in ethics. Rather, his considerations, reasons and arguments in favour of truth, facts, correspondence and reality in the later Wittgenstein's thought about ethics speak for objectivity. Brandhorst has shown that he is sensitive to the demand of not reading refutations into Wittgenstein, but he has failed to extend that sensitivity

\footnotetext{
${ }^{88}$ The analogy is meant to clarify a point about our use of "appear", and nothing more. I do not want to suggest that the analogy between seeing that something is good and seeing that something is red holds throughout.
} 
This is the preprint version of an article published in Philosophical Investigations 40 (1), 4063. The final publication is available at Wiley Online: http://onlinelibrary.wiley.com/doi/10.1111/phin.12129/abstract. Please cite the published version only.

to the case of objectivity. With respect to objectivity, Wittgenstein often problematises and asks questions without answering them, ${ }^{89}$ but he nowhere says or implies that there is no objectivity in ethics. Thus, there is room for objectivity in Wittgensteinian ethics. That Wittgensteinian ethics is compatible with the idea of objectivity in ethics should not be taken to mean that there is objectivity in ethics according to Wittgenstein. Instead, it should only be taken to mean that that cannot be excluded if Brandhorst's arguments are sound and if his recommendations for reading Wittgenstein are accepted. Brandhorst faces a dilemma: either he has to give up on or to qualify the claim that Wittgenstein's target is objectivity in ethics, or he has to provide extra reasons for thinking that Wittgenstein took considerations and arguments similar to those offered in favour of truth, etc. to be inapplicable to objectivity. ${ }^{90}$

\section{KU Leuven}

Institute of Philosophy

Kardinaal Mercierplein 2 - bus 3200

3000 Leuven

Belgium

benjamin.demesel@hiw.kuleuven.be

\section{References}

Baker, G. and P. M. S. Hacker. (2009). Wittgenstein: Rules, Grammar and Necessity, 2nd edition. Oxford: Wiley-Blackwell.

Brandhorst, M. (2015). “Correspondence to Reality in Ethics.” Philosophical Investigations 38: 227-250.

Crary, A. (2007a). "Introduction.” In A. Crary (ed.), Wittgenstein and the Moral Life: Essays in Honor of Cora Diamond. Cambridge (MA): MIT Press, pp. 1-26.

Crary, A. (2007b). "Wittgenstein and Ethical Naturalism." In G. Kahane, E. Kanterian and O. Kuusela (eds.), Wittgenstein and His Interpreters. Oxford: Wiley-Blackwell, pp. 295-319.

\footnotetext{
${ }^{89}$ See, for instance, "But is there then no objective truth?" (Wittgenstein 1975: §108) and "But is there no objective character here?” (Wittgenstein 1975: §336).

${ }^{90} \mathrm{I}$ am grateful to Stefan Rummens for his comments on an earlier version of this paper.
} 
This is the preprint version of an article published in Philosophical Investigations 40 (1), 4063. The final publication is available at Wiley Online: http://onlinelibrary.wiley.com/doi/10.1111/phin.12129/abstract. Please cite the published version only.

Crary, A. (2007c). Beyond Moral Judgment. Cambridge (MA): Harvard University Press.

Diamond, C. (1991a). "Wright's Wittgenstein." In The Realistic Spirit: Wittgenstein,

Philosophy, and the Mind. Cambridge (MA): MIT Press, pp. 205-223.

Diamond, C. (1991b). "Secondary Sense." In The Realistic Spirit: Wittgenstein, Philosophy, and the Mind. Cambridge (MA): MIT Press, pp. 225-241.

Diamond, C. (1991c). "The Face of Necessity." In The Realistic Spirit: Wittgenstein, Philosophy, and the Mind. Cambridge (MA): MIT Press, pp. 243-266.

Dummett, M. (1959). "Wittgenstein's Philosophy of Mathematics.” Philosophical Review 68: 324-348.

Fisher, A. and S. Kirchin. (2006). "Introduction.” In A. Fischer and S. Kirchin (eds.), Arguing About Metaethics. London: Routledge, pp. 1-22.

Gaita, R. (2000). A Common Humanity: Thinking About Love and Truth and Justice, 2nd edition. London: Routledge.

Gaita, R. (2004). Good and Evil: An Absolute Conception, 2nd edition. London: Routledge.

Hanfling, O. (2002). "Questions and Answers in Wittgenstein's Philosophy.” In Wittgenstein and the Human Form of Life. London: Routledge, pp. 11-22.

Johnston, P. (1989). Wittgenstein and Moral Philosophy. London: Routledge.

Johnston, P. (1999). The Contradictions of Modern Moral Philosophy: Ethics after Wittgenstein. London: Routledge.

Kirchin, S. (2012). Metaethics. Basingstoke: Palgrave Macmillan.

Leich, C. and S. Holtzman. (1981) "Introductory Essay: Communal Agreement and Objectivity." In S. Holtzman and C. Leich (eds.), Wittgenstein: To Follow a Rule. London: Routledge, pp. 1-27.

Lovibond, S. (1983). Realism and Imagination in Ethics. Oxford: Blackwell.

Lovibond, S. (2002). Ethical Formation. Cambridge (MA): Harvard University Press.

Pears, D. (1971). Wittgenstein. London: Fontana.

Rhees, R. (1965). "Some Developments in Wittgenstein's View of Ethics.” The Philosophical Review 74: 17-26.

Ripstein, Arthur. (1993). “Questionable Objectivity.” Noûs 27: 355-372.

Teichmann, R. (2001). “The Functionalist's Inner State.” In S. Schroeder (ed.), Wittgenstein and Contemporary Philosophy of Mind. Basingstoke: Palgrave Macmillan, pp. 24-35. 
This is the preprint version of an article published in Philosophical Investigations 40 (1), 4063. The final publication is available at Wiley Online: http://onlinelibrary.wiley.com/doi/10.1111/phin.12129/abstract. Please cite the published version only.

Wiggins, D. (1998). “Truth, Invention, and the Meaning of Life.” In Needs, Values, Truth: Essays in the Philosophy of Value, 3rd edition. Oxford: Clarendon Press.

Wiggins, D. (2006a). “Objectivity in Ethics.” In Twelve Lectures on the Philosophy of Morality. London: Penguin Books, pp. 325-356.

Wiggins, D. (2006b). "Miscellanea Metaethica." In Twelve Lectures on the Philosophy of Morality. London: Penguin Books, pp. 357-381.

Wittgenstein, L. (1969). The Blue and Brown Books, 2nd edition. Oxford: Blackwell.

Wittgenstein, L. (1975). On Certainty. G. H. von Wright and G. E. M. Anscombe (eds.). Oxford: Blackwell.

Wittgenstein, L. (1976). Lectures on the Foundations of Mathematics: Cambridge 1939. C.

Diamond (ed.). Chicago: Chicago University Press.

Wittgenstein, L. (1977). Remarks on Colour. G. E. M. Anscombe (ed.). Oxford: Blackwell.

Wittgenstein, L. (2009a). Philosophical Investigations, 4th edition. P. M. S. Hacker and J. Schulte (eds.). Oxford: Wiley-Blackwell.

Wittgenstein, L. (2009b). "Philosophy of Psychology - A Fragment." In Philosophical Investigations, 4th edition. P. M. S. Hacker and J. Schulte (eds.). Oxford: Wiley-Blackwell, pp. 182-243.

Wittgenstein, L. (2014) Lecture on Ethics. E. Zamuner, E. V. Di Lascio and D. K. Levy (eds.). Oxford: Wiley-Blackwell.

Wright, C. (1980). Wittgenstein on the Foundations of Mathematics. London: Duckworth. 